\title{
Epidemiological Characteristics of COVID-19 in Seremban, Negeri Sembilan, Malaysia
}

\author{
Mohd 'Ammar Insan Ahmad Zamzuri', ${ }^{1,2}$ Farah Edura Ibrahim', Muhammad Alimin Mat Reffien ${ }^{1}$, \\ Mohd Fathulzhafran Mohamed Hanan ${ }^{1}$, Muhamad Hazizi Muhamad Dasani ${ }^{2}$, Noor Khalili Mohd Ali ${ }^{2}$, Hasanain Faisal Ghazi ${ }^{3}$, \\ Mohd Rohaizat Hassan ${ }^{1 *}$ \\ ${ }^{1}$ Department of Community Health, Universiti Kebangsaan Malaysia, Kuala Lumpur, Malaysia; ${ }^{2}$ Seremban District Health Office, \\ Negeri Sembilan State Health Department, Seremban, Negeri Sembilan, Malaysia; ${ }^{3}$ College of Nursing, Al-Bayan University, \\ Baghdad, Iraq
}

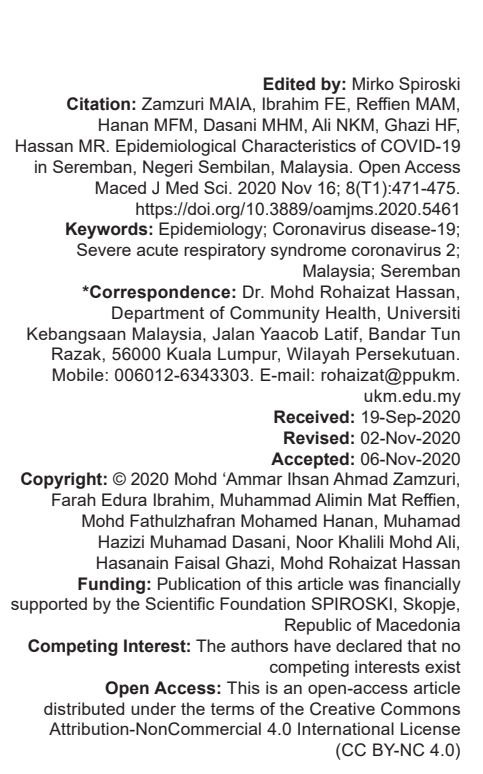

\section{Introduction}

Coronavirus disease (COVID)-19 is a global pandemic and has caused a significant impact to live, economic and social perspectives [1]. The disease transmission dynamic was beyond imagination as initial postulation centered around zoonosis etiology, but subsequent study confirmed human to human transmission [2]. Current recorded cases have surpassed three million cases worldwide, with the United States of America is on top of the chart. While vaccine development is still underway, many countries have employed containment strategy by ramping up testing, active contact tracing, isolating the exposed, as well as treating the positive case. Some countries go beyond hard policy change that limits gathering or imposing movement restriction, which has been predicted by machine learning to reduce infectivity rate by $7.8 \%$ [3].

In Malaysia, the earliest recorded cases were dated back in January 2020 and have closed contact with infected persons in Singapore. As of April 17, 2020, Malaysia has reported a total of 5251 number of cases with 86 deaths [4]. As for Seremban district, we reported the first case of COVID-19 about 3 months after the beginning of Wuhan epidemic and quickly become the top three districts with the highest number of cases in Malaysia. To date, almost all of the cases could be epidemiologically linked and pointed to a specific source of exposure. A thorough analysis to describe the characteristics of the COVID-19 case is vital to plan for focused and optimal intervention. Thus, this study provides an analysis of epidemiological data for the basis of the local prevention plan. 


\section{Methods}

This was a retrospective record review cross-sectional study from February until April 2020 obtained from the Seremban Health District Crisis and Preparedness Respond Centre Surveillance System. Each of the registered COVID-19 cases was investigated thoroughly by the Health Inspector, and subsequently, a formal report was submitted containing all the demographics and epidemiological information. The definition criteria used were in accordance with the Ministry of Health $(\mathrm{MOH})$ Malaysia guideline. A confirmed case was defined by a positive real-time reverse-transcription-polymerasechain-reaction (RT-PCR) from samples taken either through nasopharynx swab or oropharynx swab. An asymptomatic COVID-19 case was defined as a positive RT-PCR but without clinical symptom. A cluster of COVID-19 was defined as two or more confirmed cases or asymptomatic cases found with strong epidemiological linkage, that is, significantclose contact with positive cases or have travel history to an epidemic country (World Health Organization).

\section{Statistical analysis}

All the data were extracted and tabulated into Microsoft Excel 365 and licensed SPSS version 23.0 (borne by the author) was used in data analysis and producing relevant chart. The epidemiological characteristic and trend were described. Chi-square test was done to compare the sociodemographic difference between the red zone and non-red zone area.

\section{Ethical approval}

The study has been approved by the Medical Research and Ethics Committee of the MOH Malaysia and registered with the National Medical Research Register.

\section{Result}

\section{COVID-19 incidence, mortality, and case- fatality rates (CFR)}

As of April 10, 2020, a total of 214 number of COVID-19 cases were reported in Seremban district that account for $69.3 \%$ of the total number of cases for the whole state of Negeri Sembilan. However, these 214 cases were unevenly distributed among eight subdistricts; that is, sub-district Ampangan recorded the highest number of cases (76 cases) while sub-district Lenggeng only recorded 9 cases of COVID-19, Figure 1.

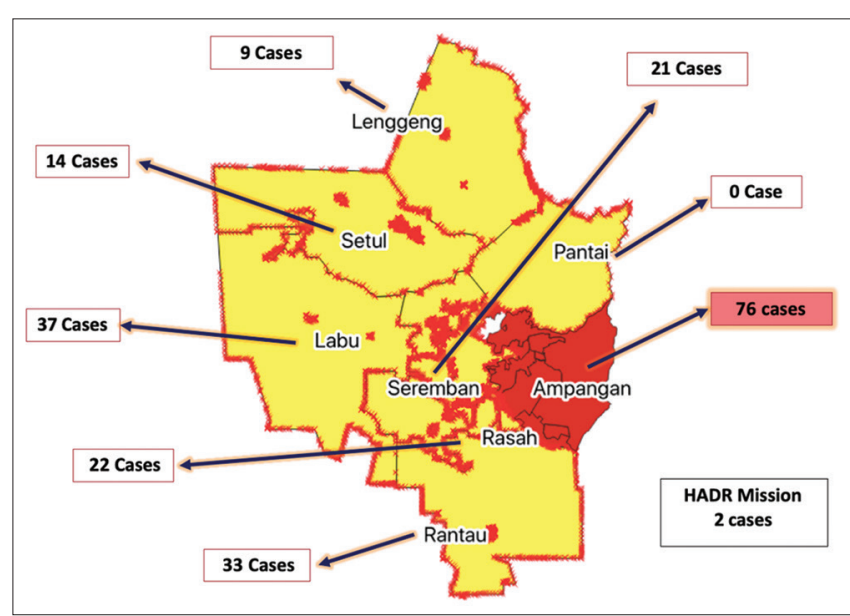

Figure 1: Distribution of coronavirus disease-19 cases in Seremban district as of April 10, 2020

Therefore, mapping of the area based on a number of cases has been used by the MOH Malaysia to allow stratification of the risk. By definition, sub-district with recorded more than 41 number of COVID-19 cases will be classified as a red zone area. The red zone area is considered high risk for the spread of COVID-19 as more than 41 COVID-19 cases were clustered in the area and have the potential to become a new epicenter of the outbreak if it is not well controlled. To date, only sub-district Ampangan was registered as a red zone area for the district of Seremban. The demographic and characteristic of all the cases were described in Table 1.

Table 1: Demographic and characteristic of COVID-19 patients

\begin{tabular}{|c|c|c|c|c|}
\hline Variables & $\begin{array}{l}\text { Red zone } \\
n=78(\%)\end{array}$ & $\begin{array}{l}\text { Non red zone } \\
n=136(\%)\end{array}$ & $\chi^{2}$ & $p$-value \\
\hline Age, y, mean (SD) & $44.9(17.6)$ & $42.4(17.6)$ & 0.985 & $0.33^{*}$ \\
\hline Age, $y$, range & & & 2.225 & 0.56 \\
\hline$\leq 19$ & $8(10.3)$ & $12(8.8)$ & & \\
\hline 20-39 & $19(24.4)$ & $46(33.8)$ & & \\
\hline $40-59$ & $34(43.6)$ & $51(37.5)$ & & \\
\hline$\geq 60$ & $17(21.8)$ & 27 (19.9) & & \\
\hline Gender & & & 0.247 & 0.67 \\
\hline Male & $42(53.8)$ & $78(57.4)$ & & \\
\hline Female & $36(46.2)$ & $58(42.6)$ & & \\
\hline Ethnicity & & & 14.162 & $0.001^{\#}$ \\
\hline Malay & $76(97.4)$ & $113(83.1)$ & & \\
\hline India & $0(0.0)$ & $12(8.8)$ & & \\
\hline Chinese & $2(2.6)$ & $3(2.2)$ & & \\
\hline Non-citizen & $0(0.0)$ & $8(5.9)$ & & \\
\hline Co-morbidity & & & 0.758 & $0.90^{\#}$ \\
\hline None & $57(73.1)$ & $100(73.5)$ & & \\
\hline 1 Co-morbid & $9(11.5)$ & $15(11.0)$ & & \\
\hline 2 Co-morbid & $9(11.5)$ & $18(13.2)$ & & \\
\hline$\geq 3$ Co-morbid & $3(3.8)$ & $3(2.2)$ & & \\
\hline Symptoms & & & 0.216 & 0.93 \\
\hline Asymptomatic & $30(38.5)$ & $54(39.7)$ & & \\
\hline Fever only & $10(12.8)$ & $19(14.0)$ & & \\
\hline Fever with any URTI symptom & $21(26.9)$ & $33(24.3)$ & & \\
\hline No fever but with URTI symptom & $14(17.9)$ & $25(18.4)$ & & \\
\hline Other symptoms & $3(3.8)$ & $5(3.7)$ & & \\
\hline
\end{tabular}

The incidence rate of COVID-19 in Seremban district for the first wave of outbreak as of April 10, 2020 , was 311 cases per 1,000,000 population. There was 5 recorded death due to COVID-19, which makes the CFR of $2.3 \%$. All mortality cases were Malaysian, Malay race, age range 41-64-year-old and had a significant co-morbidity of chronic disease. 


\section{Distribution of COVID-19 cases by onset and diagnosis}

On $4^{\text {th }}$ March marked the beginning of widespread of COVID-19 local transmission. Based on Figure 2, it is crystal clear to notice the earlier rapid rise in the number of onsets before the spikes in the number of detected cases. Nevertheless, toward the end of the phase, the number of cases has exceeded the number of onsets as a result of an extensive active contact tracing program conducted by the Seremban Health District Office. As per $\mathrm{MOH}$ guideline, all positive cases of COVID-19 will be admitted to the designated hospital and received standard treatment protocol based on severity classification.

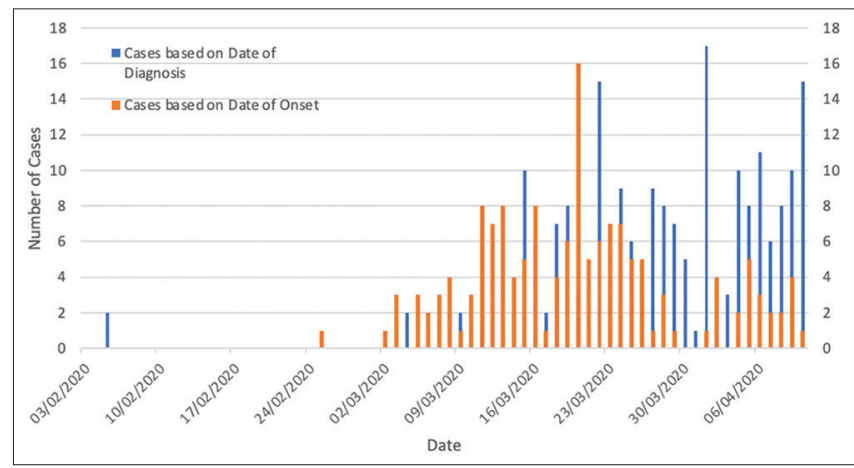

Figure 2: Epidemiology curve showing distribution trend of coronavirus disease-19 cases based on date of diagnosis and date of first symptom onset

\section{Distribution of cases of COVID-19 by identified clusters}

The two earliest recorded COVID-19 cases in Seremban district (based on Figure 2) were from Humanitarian Assistance and Disaster Relief mission that was aimed to retrieve the Malaysians which was stranded in Wuhan, the epicenter of the COVID-19 world pandemic. Both of them were treated in the Seremban General Hospital. A total of 107 passengers were brought home during the mission, and those with no acute illness and negative COVID-19 test has undergone 14-days of quarantine in a designated academy in Seremban. The first wave of local transmission began in early March arise from the cluster of multi-conglomerate cases. Only three registered cases in Seremban district were attributed to this cluster as those who involve were limited to the board members of the company. Hence, the circle of contact was scared. Immediately after, the ongoing transmission of local COVID-19 spread to date has been largely attributed to a cluster of Islamic congregations gathering at Sri Petaling that was assumed to house as many as 16,000 participants. This cluster accounted for $72.3 \%$ (157 cases) of the total registered cases in Seremban. Despite all this, only 8 cases of COVID-19 in Seremban district were attributed to healthcare worker (HCW).

Further analysis to compare sociodemographic differences among patients who live in red zone and non-red zone area revealed no statistically significant result for all the variables measure except for ethnicity. Malay race was particularly affected during the first wave of COVID-19 outbreak in Seremban district for both red zone and non-red zone area.

\section{Discussion}

Many nations employed total lockdown or massive restriction of movement approach to combat the unprecedented COVID-19 outbreak worldwide. Despite the health benefits in controlling the disease, it causes severe economic disruption to the nation that can lead to a recession. Hence, there should be a balance in employing public health countermeasures when striking COVID-19 pandemic. Early diagnosis will lead to early treatment and rapid isolation of the confirmed cases. Mass screening may not be possible during the early phase of an outbreak due to unpreparedness to handle such event. Thus, targeted screening approach is best suited to achieve the early detection goal. However, a set of criteria need to be established to ensure a suitable target group. This can be done by studying the epidemiology of the current outbreak and subsequently translate the findings to be used at ground zero (field).

One of the initial steps taken by the $\mathrm{MOH}$ in response to the growing outbreak is to stratify the district into three categories, namely red zone, yellow zone, and green zone (zero COVID-19 cases). Each zone received similar public health interventions, but the red zone areas were given more priority due to the highest potential risk of COVID-19 transmission. Furthermore, it was observed that the red zone area in Seremban is densely populated.

Our study found that a higher proportion of cases affected were adult group (mean aged 43 years) regardless of the zones. The finding is similar to other studies done before [2], [5], [6]. [7]. These groups of population are likely to be inactive and constant contact with the world due to their nature as the working population and the breadwinner of the family [8]. Hence, making them more susceptible to COVID-19 infection and subsequently passes on the transmission to other family members [9]. Despite the fact that the proportion of male is seen to be more than female who contracted COVID-19 for both zones, but it was not statistically significant. This could be due to the unspecific nature of virus pathophysiology with no selective gender preferences, as seen in other epidemiological studies [7], [10], [11], [12].

Apart from that, our study revealed that the risk of getting COVID-19 infection did not associate with the presence of co-morbidity of a person. Therefore, it should be an alarming feature for everyone to be more vigilant to look after themselves. Although the risk of 
infection is less affected by the variable, there is growing evidence that co-morbidity may lead to poorer outcome such as in severe cases and mortality cases; especially those with hypertension or diabetes [13], [14].

In Seremban district, Malay ethnicity represents a significant proportion of COVID-19 cases as compare to the others. The figure is not serendipitous as simple reasoning might be caused by a disproportionate population composition of the country. However, the main explanation was that the Malays ethnicity made up $100 \%$ of the participants in the major outbreak; Islamic congregation at Sri Petaling mosque. Hence, by applying the possible mean reproduction time (R0) and the secondary attack rate, the number may increase by at least a factor of 2 [15], [16]. Although COVID-19 cluster among HCW was very minimal, the fraternity must not be too complacent but continue to be vigilant to ensure uncompromised manpower. To ensure minimal exposure risk of the medical personnel, they must have abundant access to all the personal protective gear [17], [18] that is suitable for the threat that they are facing. Nevertheless, they need to be given sufficient education, training, and updated information about COVID-19.

Overall, there is no difference in terms of clinical presentation between the zones. Common presentations were fever and upper respiratory symptoms, which are similar findings in other studies [2] [11], [12], [19]. However, the proportion of asymptomatic patients was the highest in our study due to the extensive contact tracing program. The health authority will activate an active case detection protocol each time a COVID-19 test came back positive. Nevertheless, proactive action by the Seremban Health District conducting a continuous screening program at the entry border, regardless of symptom presentation, led to higher detection of asymptomatic cases [20].

The ultimate aim of early detection, early treatment, and rapid isolation of positive cases is to quickly break down the chain of transmission. The cost of such interventions is very much less if more population are infected with COVID-19 and ended up being treated in the hospital or intensive care unit. In response to the pandemic, the Malaysian health authority has been collaborating with other agencies to achieve the goals. Mobilization of human resources and utilizing vehicles from other departments to be used for targeted screening and isolating confirmed cases were made possible from good national leadership. Quarantine centers were set up to monitor the highrisk relatives or contacts to the positive cases. These people underwent COVID-19 testing after careful epidemiology links were established with the confirmed cases. As mentioned, early detection of COVID-19 cases before symptom development is key to flatten the epidemiology curve when there is evidence of presymptomatic transmission of the virus [21].
As mentioned, the factor that triggered the spread of COVID-19 infection within Seremban district in this first wave of the outbreak was related to a religious gathering. Despite no reported any ill attendee during the 3-day event, the resultant outcome of COVID-19 infection was still catastrophic. Combining the mode of transmission and the pre-symptomatic transmission of the virus, it would easily make one at risk for the infection by just being in close proximity with an index case. The situation will be made worse if no space available for social distancing, inadequate hand hygiene facility, or improper usage of face mask by those attending the event. Hence, it is recommended to postpone any informal activities involving huge gathering and held in a confined space until COVID-19 curve has flattened.

Our findings should be interpreted carefully due to some limitations. The primary limitation is that our data only limited to only 234 confirmed cases which were bounded to the set of culture and tradition of Seremban population. This single-center (district) study limits the number of samples. Finally, detailed clinical information was not available due to a lack of follow-up.

\section{Conclusion}

Based on our data analysis, COVID-19 infection was easily transmitted in Seremban district following the introduction of a potential source to a susceptible population. The first wave of local transmission occurred abruptly. The epidemiology of the outbreak was largely skewed toward a certain particular race group. A rapid and coordinated response by the health authority in collaboration with other relevant agencies has successfully made early detection of cases before symptom presentation. This strategy, together with the quarantine of those exposed with a negative result, as well as isolating and treating the positive cases, will ultimately break the chain of transmission. Nevertheless, individual and community must play their biggest part by keeping safe distance social distancing, frequent handwashing or sanitizing, and keeping good cough or sneeze etiquette.

\section{Acknowledgment}

The authors would like to thank the DirectorGeneral of Health Malaysia for permission to publish this paper. Furthermore, authors would like to thank the Seremban District $\mathrm{MOH}$ together with all the dedicated staffs and State Health Director of Negeri Sembilan for allowing to conduct this study. 


\section{References}

1. Chakraborty I, Maity P. COVID-19 outbreak: Migration, effects on society, global environment and prevention. Sci Total Environ. 2020;728:138882. https://doi.org/10.1016/j. scitotenv.2020.138882

PMid:32335410

2. Guan WJ, Ni ZY, Hu Y, Liang WH, Ou CQ, He JX, et al. Clinical characteristics of coronavirus disease 2019 in China. N Engl J Med. 2020;382(18):1708-20.

3. Cobb JS, Seale MA. Examining the effect of social distancing on the compound growth rate of COVID-19 at the county level (United States) using statistical analyses and a random forest machine learning model. Public Health. 2020;185:27-9. https:// doi.org/10.1016/j.puhe.2020.04.016

PMid:32526559

4. Elengoe A. COVID-19 outbreak in Malaysia. Osong Public Health Res Perspect. 2020;11(3):93-100. https://doi.org/10.24171/j. phrp.2020.11.3.08 PMid:32494567

5. Cao C, Li Y, Liu S, Fan H, Hao L. Epidemiologic features of 135 patients with coronavirus disease (COVID-19) in Tianjin, China. Disaster Med Public Health Prep 2020:1-5. https://doi. org/10.1017/dmp.2020.63

PMid:32234107

6. Jia J, Hu X, Yang F, Song X, Dong L, Zhang J, et al. Epidemiological characteristics on the clustering nature of COVID-19 in Qingdao city, 2020: A descriptive analysis. Disaster Med Public Health Prep. 2020:1-5. https://doi. org/10.1017/dmp.2020.59

PMid:32228732

7. Gold JA, Wong KK, Szablewski CM, Patel PR, Rossow J, da Silva J, et al. Characteristics and clinical outcomes of adult patients hospitalized with COVID-19-Georgia, March 2020. MMWR Morb Mortal Wkly Rep. 2020;69(18):545-50. https://doi. org/10.15585/mmwr.mm6911a1

8. Loichinger E, Hammer B, Prskawetz A, Freiberger M, Sambt J. Quantifying economic dependency. Eur J Popul. 2017;33(3):351-80. https://doi.org/10.1007/s10680-016-9405-1 PMid:30976232

9. Yu P, Zhu J, Zhang Z, Han Y, Huang L. A familial cluster of infection associated with the 2019 novel coronavirus indicating potential person-to-person transmission during the incubation period. J Infect Dis. 2020;221(11):1757-61. https://doi. org/10.1093/infdis/jiaa077

PMid:32067043

10. Gemelli NA. Management of COVID-19 outbreak in argentina: The beginning. Disaster Med Public Health Prep. 2020:1-3. https://doi.org/10.1017/dmp.2020.116

PMid:32317041

11. Li X, Wang X, Liu J, Huang G, Shi X. Epidemiological characteristics of confirmed COVID-19 in Guizhou Province, China. Disaster Med Public Health Prep. 2020:1-19. https://doi. org/10.1017/dmp.2020.134

PMid:32367793

12. Escalera-Antezana JP, Lizon-Ferrufino NF, Maldonado-AlanocaA, Alarcón-De-la-Vega G, Alvarado-Arnez LE, Balderrama-Saavedra $\mathrm{MA}$, et al. Clinical features of the first cases and a cluster of coronavirus disease 2019 (COVID-19) in Bolivia imported from Italy and Spain. Travel Med Infect Dis. 2020;35:101653. https:// doi.org/10.1016/j.tmaid.2020.101653

PMid:32247926

13. Zhou F, Yu T, Du R, Fan G, Liu Y, Liu Z, et al. Clinical course and risk factors for mortality of adult inpatients with COVID-19 in Wuhan, China: A retrospective cohort study. Lancet. 2020;395(10229):1054-62. https://doi.org/10.1016/ s0140-6736(20)30566-3

PMid:32171076

14. Fang L, Karakiulakis G, Roth M. Are patients with hypertension and diabetes mellitus at increased risk for COVID-19 infection? Lancet Respir Med 2020;8(4):e21. https://doi.org/10.1016/ s2213-2600(20)30116-8

PMid:32171062

15. Liu Y, Eggo RM, Kucharski AJ. Secondary attack rate and superspreading events for SARS-CoV-2. Lancet. 2020;395(10227):e47. https://doi.org/10.1016/ s0140-6736(20)30462-1

PMid:32113505

16. Shim E, Tariq A, Choi W, Lee Y, Chowell G. Transmission potential and severity of COVID-19 in South Korea. Int J Infect Dis. 2020;93:339-44. https://doi.org/10.1101/2020.02.27.20028829

17. Liew MF, Siow WT, MacLaren G, See KC. Preparing for CovID-19: Early experience from an intensive care unit in Singapore. Crit Care. 2020;24(1):1-3. https://doi.org/10.1186/ s13054-020-2814-x PMid:32151274

18. Kwon KT, Ko JH, Shin H, Sung M, Kim JY. Drive-through screening center for covid-19: A safe and efficient screening system against massive community outbreak. J Korean Med Sci. 2020;35(11):e123. https://doi.org/10.3346/jkms.2020.35. e123 PMid:32193904

19. Hu Z, Song C, Xu C, Jin G, Chen $Y, X u X$, et al. Clinical characteristics of 24 asymptomatic infections with COVID-19 screened among close contacts in Nanjing, China. Sci China Life Sci. 2020;63(5):706-11. https://doi.org/10.1007/ s11427-020-1661-4 PMid:32146694

20. Bi Q, Wu Y, Mei S, Ye C, Zou X, Zhang Z, et al. Epidemiology and transmission of COVID-19 in 391 cases and 1286 of their close contacts in Shenzhen, China: A retrospective cohort study. Lancet Infect Dis. 2020;20(8):911-9. https://doi.org/10.1016/ s1473-3099(20)30287-5

21. Danis K, Epaulard O, Bénet T, Gaymard A, Campoy S, Bothelo-Nevers E, et al. Cluster of coronavirus disease 2019 (Covid-19) in the French Alps, February 2020. Clin Infect Dis. 2020;71(15):825-32.

PMid:32277759 